\title{
Spectroscopic Evaluation of the Molecular Structures of di- $\mu$-Chlorobis(1,5-Cyclooctadiene) Iridium (I) and Rhodium (I) Complexes
}

\author{
Saheed A. Popoola, Abdulaziz A. Al-Saadi* \\ Chemistry Department, King Fahd University of Petroleum and Minerals, Dhahran, KSA \\ Email: ${ }^{*}$ asaadi@kfupm.edu.sa
}

Received 14 October 2014

\begin{abstract}
Vibrational and H-NMR spectroscopic studies on di- $\mu$-chlorobis(1,5-cyclooctadiene) of iridium(I) and rhodium (I) complexes have been carried out. In addition, the two $D_{2 h}$ and $D_{2}$ structures for both complexes have been fully optimized. It was expected from the single-molecule vapor-phase density functional theory (DFT) calculation that the $D_{2}$ structure is more stable by $5-6 \mathrm{kcal} / \mathrm{mol}$. While spectroscopic analysis study confirms that in the solid phase, the two complexes retain the higher $D_{2 h}$ symmetry. The vibrational wavenumbers of certain modes associated to free 1,5-cyclooctadiene were observed to be shifted to lower values upon coordination with rhodium or iridium metals. It was also found theoretically that the metal-olefin interaction is slightly more pronounced for iridium metal.
\end{abstract}

\section{Keywords}

1,5-Cyclooctadiene, DFT Calculations, Iridium and Rhodium Binuclear Complexes, Infrared and Raman Spectra

\section{Introduction}

Di- $\mu$-chlorobis(1,5-cyclooctadiene) of iridium (I) and rhodium (I) ions are popular complexes which are employed in several homogenous catalytic reactions. They are mostly used as precursor catalysts in the development of catalytic systems for applications in different reactions well-reported in the literature [1]-[3]. The importance of these two complexes has attracted the attention to explore their structural and vibrational properties over the past years. A crystallographic study showed that both complexes retain $D_{2 h}$ symmetry in the solid phase [4]-[6]. An infrared study on the assignments of $v(\mathrm{C}=\mathrm{C}), v(\mathrm{M}-\mathrm{Cl})$ and $v(\mathrm{M}$-olefin) vibrations [7] as well as the strength of metal-olefin bond interaction was also reported [8]. These studies showed that the molecular symmetry plays a role in understanding the electronic, structural properties as well as the catalytic activity. In the same

\footnotetext{
*Corresponding author.
}

How to cite this paper: Popoola, S.A. and Al-Saadi, A.A. (2015) Spectroscopic Evaluation of the Molecular Structures of di- $\mu$-Chlorobis(1,5-Cyclooctadiene) Iridium (I) and Rhodium (I) Complexes. Journal of Applied Mathematics and Physics, 3, 140-144. http://dx.doi.org/10.4236/jamp.2015.32021 
sense, the symmetry of the diolefinic ligands used in complex build-up is essential in determining the symmetry of resulting complex. 1,5-cyclooctadiene (COD) was reported to have $C_{2 v}$ symmetry in tub form but $C_{i}$ in chair configuration [7] [8]. It commonly exits as $C_{2 v}$ tub configuration in both liquid and solid states [7] for complexation, which results in $D_{2 h}$ symmetry (Figure 1(a)) explained in literature for di- $\mu$-chlorobis(1,5-cyclooctadiene) of both iridium (I), $[\operatorname{Ir}(\mu-\mathrm{Cl}) \mathrm{COD}]_{2}$, and rhodium (I), $[\mathrm{Rh}(\mu-\mathrm{Cl}) \mathrm{COD}]_{2}$ [7] [8]. Further analysis of the infrared and H-NMR spectra of the two complexes has been carried out, and the Raman spectra of the solid phase have been collected and interpreted. In this paper we highlight some of our findings which will be detailed in future in another article.

\section{Experimental}

The complex synthesis was carried out under an inert atmosphere with use of Schlenk-tube technique. All the chemicals used for this research work were purchased from Sigma Aldrich Chemicals and used without further purification while the solvents used in the synthesis were first purified using standard procedures and distilled under argon before use.

\subsection{Synthesis of $[\operatorname{Ir}(\mu-\mathrm{Cl}) \mathrm{COD}]_{2}$}

$6 \mathrm{~mL}$ of distilled water, $2.2 \mathrm{~mL}$ of isopropanol and $1.2 \mathrm{~mL}$ of 1,5-cyclooctadiene were measured into $50 \mathrm{~mL}$ two neck round bottomed flask. The solvent mixture was first purged with argon after which a condenser was connected to the flask. Then, the mixture was refluxed for 1 hour prior to the addition of $1 \mathrm{~g}$ of $\operatorname{IrCl}_{3}$ and further refluxed for 8 hours after the addition under strong stirring. The suspended liquid was removed via cannula and the cold methanol was added to red oil left to effect formation of red crystalline solid. The solid was later filtered, washed with cold methanol and dried under vacuum.

\subsection{Synthesis of $[\mathrm{Rh}(\mu-\mathrm{Cl}) \mathrm{COD}]_{2}$}

$1 \mathrm{~g}$ of $\mathrm{RhCl}_{3}$ was weighed in $50 \mathrm{~mL}$ two neck round bottomed flask fitted with condenser, then vacuumed and filled with argon. Then, $10 \mathrm{~mL}$ of ethanol, $2 \mathrm{~mL}$ of distilled water and $1.4 \mathrm{~mL}$ of 1,5-cyclooctadiene were added into the flask. Thereafter, the reaction mixture was refluxed for 8 hours under strong stirring. The resulting yellow precipitate was filtered, washed with distilled water and ethanol and dried under high vacuum.

\subsection{Characterization}

The NMR analysis of the deuterated chloroform solution of the two synthesized complexes was carried. The infrared spectrum of 1,5-cyclooctadiene was recorded through smart orbit technique while two complexes were sampled in $\mathrm{KBr}$ pellets. Raman spectra for the cyclooctadiene and the two complexes were recorded for sample in a $1 \mathrm{~mm}$ glass tube using a laser source of $1064 \mathrm{~nm}$ with $0.3 \mathrm{~W}$ power.

\subsection{Computation}

Ab initio density functional theory (DFT) calculations at B3LYP level were performed on the molecules using Gaussian 09 program [9]. Optimization was carried out using basis set of $6-311++\mathrm{G}(\mathrm{d}, \mathrm{p})$ for the nonmetals and SDD for the transition metals. The same basis sets were used for vibrational frequency calculations with the population analysis being undertaken through full natural bond orbital analysis calculation while the NMR was computed using Gauge-Independent Atomic Orbital (GIAO) method. The Polarizable Continuum Model (PCM) using the integral equation formalism variant (IEF) was implemented to predict the solvent effect on the theoretical spectral data for both complexes.

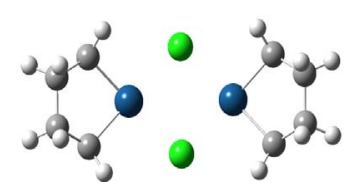

(a)

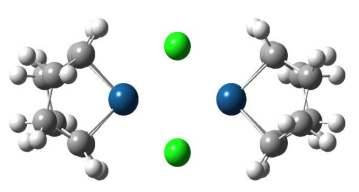

(b)

Figure 1. The two symmetries of $[\mathrm{M}(\mu-\mathrm{Cl}) \mathrm{COD}]_{2} ; \mathrm{M}=\mathrm{Ir}$ or Rh (blue); Cl (green), C (gray). (a) $D_{2 h}$; (b) $D_{2}$. 


\section{Results and Discussion}

\subsection{Geometry}

Two symmetries $D_{2}$ and $D_{2 h}$ were fully optimized and their relative energies are shown in Table 1. The $D_{2}$ configuration is predicted to be more stable in the gas phase compared to $D_{2 h}$ by 5.88 and $5.04 \mathrm{kcal} / \mathrm{mol}$, respectively for $[\mathrm{Rh}(\mu-\mathrm{Cl})(\mathrm{COD})]_{2}$ and $[\operatorname{Ir}(\mu-\mathrm{Cl})(\mathrm{COD})]_{2}$. The $D_{2}$ symmetry is obtained from the $C_{i} \mathrm{COD}$, while the $D_{2 h}$ complex is associated with $C_{2}$ COD [7] [8].

The ${ }^{1} \mathrm{H}$ NMR calculations were carried out for the two configurations of both complexes in gas phase and in $\mathrm{CHCl}_{3}$ solvent using the PCM model and compared to the experimental ones. Three sets of $8 \mathrm{H}$ peaks for $D_{2 h}$ symmetry but six sets of $4 \mathrm{H}$ peaks for $D_{2}$ symmetry were predicted (Table 2). These sets have different chemical environments. The $D_{2 h}{ }^{1} \mathrm{H}$ NMR result is in agreement with the theoretical ${ }^{1} \mathrm{H}$ NMR spectra for both complexes confirming the higher level symmetry even in solution phase. It is also interesting to notice that the average shielding values for the $D_{2}$ configuration matches with shielding value of each set in that of $D_{2 h}$ as depicted in Table 2.

\subsection{Vibration}

Selected modes of vibrations associated with $\mathrm{C}=\mathrm{C}$ and $\mathrm{C}-\mathrm{H}$ bonds of COD were followed theoretically and experimentally for the free configuration and coordinated ones in the complex as indicated in Table 3 . There is a quite agreement between the two methods for the \% shift in frequency depicted in Table 4 . All the corresponding frequencies of mode of vibrations in the free diolefin shift to lower values in the complex with the exception of out-of-plane wagging in both complexes. The sum of shift in $\mathrm{C}=\mathrm{C}$ stretch (in-phase) and C-H in-plane wag (inplane) frequencies between the free olefin and coordinated one reflects the total $(\sigma+\pi)$ metal-olefin interaction [8]. There is agreement between the sums obtained from theoretical calculation and experiment with $[\operatorname{Ir}(\mu-\mathrm{Cl})(\mathrm{COD})]_{2}$ (13\%) having slightly higher value than $[\mathrm{Rh}(\mu-\mathrm{Cl})(\mathrm{COD})]_{2}(12 \%)$ while its \% shift in out of plane wag almost twice that of Rh complex. These results indicate a stronger metal-olefin interaction for Ir complex. This conclusion is ascertained by results obtained from natural bond orbital (NBO) calculation with hybridization values of carbons in $\mathrm{C}=\mathrm{C}$ and $\mathrm{C}-\mathrm{H}$ of the Ir complex being higher than those in the Rh complex as seen in Table 5. Iridium

Table 1. Optimization energy for different configurations of the complexes.

\begin{tabular}{|c|c|c|c|c|c|}
\hline \multicolumn{3}{|c|}{$[\mathrm{Rh}(\mu-\mathrm{Cl})(\mathrm{COD})]_{2}$} & \multicolumn{3}{|c|}{$[\operatorname{Ir}(\mu-\mathrm{Cl})(\mathrm{COD})]_{2}$} \\
\hline Configuration & Energy & Relative Energy & Configuration & Energy & Relative Energy \\
\hline & (Hartree) & $(\mathrm{kcal} / \mathrm{mol})$ & & (Hartree) & (kcal/mol) \\
\hline$D_{2}$ & -1766.07 & 0.00 & $D_{2}$ & -1753.68 & 0.00 \\
\hline$D_{2 h}$ & -1766.06 & 5.88 & $D_{2 h}$ & -1753.67 & 5.04 \\
\hline
\end{tabular}

Table 2. Shielding values for ${ }^{1} \mathrm{H}$ NMR peaks in ppm.

\begin{tabular}{cccccccc}
\hline & \multicolumn{2}{c}{$[\mathrm{Rh}(\mu-\mathrm{Cl})(\mathrm{COD})]_{2}$} & & \multicolumn{3}{c}{$[\operatorname{Ir}(\mu-\mathrm{Cl})(\mathrm{COD})]_{2}$} \\
\hline Peak & Experiment & $D_{2 h}$ & $D_{2}$ (Averaged) & Peak & Experiment & $D_{2 h}$ & $\mathrm{D}_{2}($ Averaged) \\
\hline 1st & 1.73 & 1.97 & 1.83 & $1 \mathrm{st}$ & 1.51 & 1.88 \\
2nd & 2.46 & 2.59 & 2.76 & 2 nd & 2.25 & 2.45 & 2.53 \\
3rd & 4.2 & 3.76 & 3.64 & 3rd & 4.21 & 3.31 & 3.27 \\
\hline
\end{tabular}

Table 3. Vibrational assignment for some selected modes of vibration around $\mathrm{C}=\mathrm{C}$ in $\mathrm{cm}^{-1}$.

\begin{tabular}{|c|c|c|c|c|c|c|c|c|c|c|c|}
\hline \multirow[b]{3}{*}{ Mode } & \multicolumn{3}{|c|}{ Cyclooctadiene } & \multicolumn{4}{|c|}{$[\mathrm{Rh}(\mu-\mathrm{Cl})(\mathrm{COD})]_{2}$} & \multicolumn{4}{|c|}{$[\operatorname{Ir}(\mu-\mathrm{Cl})(\mathrm{COD})]_{2}$} \\
\hline & \multicolumn{2}{|c|}{ Experiment } & \multirow{2}{*}{$\begin{array}{l}\text { Calculated } \\
\text { Frequency }\end{array}$} & \multicolumn{2}{|c|}{ Experiment } & \multicolumn{2}{|c|}{ Calculated Frequency } & \multicolumn{2}{|c|}{ Experiment } & \multicolumn{2}{|c|}{ Calculated Frequency } \\
\hline & IR & Raman & & IR & Raman & $\mathrm{D}_{2 \mathrm{~h}}$ & $\mathrm{D}_{2}$ & IR & Raman & $\mathrm{D}_{2 \mathrm{~h}}$ & $\mathrm{D}_{2}$ \\
\hline$v(\mathrm{C}-\mathrm{H})^{\mathrm{a}}$ & 3005 (s) & 3008 (s) & 3007 (26.19) & 2994 (s) & & $3005(7.0)$ & $3004(5.0)$ & 2975 (s) & & $2988(16.0)$ & $2987(27.1)$ \\
\hline$v(\mathrm{C}=\mathrm{C})^{\mathrm{b}}$ & & $1659(w)$ & $1672(5.1)$ & & $1468(\mathrm{~m})$ & $1488(0.18)$ & $1494(6.7)$ & & $1448(w)$ & $1462(0.11)$ & $1469(0.6)$ \\
\hline$v(\mathrm{C}-\mathrm{H})^{\mathrm{c}}$ & & $1407(w)$ & $1403(0.5)$ & & $1370(w)$ & $1384(0.3)$ & $1386(0.2)$ & & $1362(\mathrm{w})$ & $1376(0.3)$ & $1378(0.2)$ \\
\hline$v(\mathrm{C}-\mathrm{H})^{\mathrm{d}}$ & $1234(w)$ & $1238(\mathrm{vw})$ & $1231(0.0)$ & $1227(w)$ & & $1222(1.0)$ & $1196(5.0)$ & $1230(w)$ & & $1217(0.0)$ & $1191(1.0)$ \\
\hline$v(\mathrm{C}-\mathrm{H})^{\mathrm{f}}$ & $824(w)$ & $824(w(s h))$ & 834 (3.27) & & $880(\mathrm{~m})$ & $888(0.9)$ & $881(0.9)$ & $916(\mathrm{~m})$ & & $930(0.7)$ & $922(0.8)$ \\
\hline
\end{tabular}

Mode of Vibrations: ${ }^{\mathrm{a}}$ : asymmetric stretch; ${ }^{\mathrm{b}}$ : symmetric stretch; ${ }^{\mathrm{c}}$ : in-plane wag; ${ }^{\mathrm{d}}$ : in-plane wag; ${ }^{\mathrm{e}}$ : out-of-plane wag. 
Table 4. Percent (\%) shift in frequency between free 1,5-cyclooctadiene and complex.

\begin{tabular}{ccccc}
\hline & \multicolumn{2}{c}{$[\mathrm{Rh}(\mu-\mathrm{Cl})(\mathrm{COD})]_{2}$} & \multicolumn{1}{c}{$[\operatorname{Ir}(\mu-\mathrm{Cl})(\mathrm{COD})]_{2}$} \\
\hline Mode & Experiment & Calculated & Experiment & Calculated \\
\hline$v(\mathrm{C}-\mathrm{H})$ stretch & 0.37 & 0.07 & 1.00 & 0.63 \\
$v(\mathrm{C}=\mathrm{C})$ stretch & 11.51 & 11.00 & 12.72 & 12.56 \\
$v(\mathrm{C}-\mathrm{H})$ wag (in-plane) & 2.63 & 1.35 & 3.20 & 1.92 \\
$v(\mathrm{C}-\mathrm{H})$ wag (in-plane) & 0.57 & 0.73 & 0.32 & -1.14 \\
$v(\mathrm{C}-\mathrm{H})$ wag (out-of-plane) & -6.80 & -6.47 & -11.17 & -11.51 \\
\hline
\end{tabular}

Table 5. Natural bond orbital analysis for 1,5-cyclooctadiene and complex.

\begin{tabular}{|c|c|c|c|c|}
\hline Molecule & Orbital & Occupancy (e) & Bond Polarization (\%) & Hybridization \\
\hline \multirow[t]{3}{*}{ Cycoocatdiene $\left(\mathrm{C}_{2 \mathrm{v}}\right)$} & $\mathrm{C} 1-\mathrm{C} 2$ & 1.98 & C1, 70.7; C2, 70.7 & $\mathrm{C} 1, \mathrm{sp}^{1.54} ; \mathrm{C} 2, \mathrm{sp}^{1.54}$ \\
\hline & C1-H1 & 1.98 & C1, 77.3; H1, 63.5 & $\mathrm{C} 1, \mathrm{sp}^{2.59} ; \mathrm{H} 1, \mathrm{~s}$ \\
\hline & C2-H2 & 1.98 & C2, 77.3; H2, 63.5 & $\mathrm{C} 2, \mathrm{sp}^{2.59} ; \mathrm{H} 2, \mathrm{~s}$ \\
\hline \multirow[t]{3}{*}[\mathrm{Rh}(\mu-\mathrm{Cl})(\mathrm{COD})]{$_{2}\left(\mathrm{D}_{2 \mathrm{~h}}\right)$} & $\mathrm{C} 1-\mathrm{C} 2$ & 1.97 & $\mathrm{C} 1,70.7 ; \mathrm{C} 2,70.7$ & $\mathrm{C} 1, \mathrm{sp}^{2.02} ; \mathrm{C} 2, \mathrm{sp}^{2.02}$ \\
\hline & C1-H1 & 1.96 & C1, 78.3; H1, 62.3 & $\mathrm{C} 1, \mathrm{sp}^{2.73} ; \mathrm{H} 1, \mathrm{~s}$ \\
\hline & $\mathrm{C} 2-\mathrm{H} 2$ & 1.96 & C2, 78.3; H2, 62.3 & $\mathrm{C} 2, \mathrm{sp}^{2.73} ; \mathrm{H} 2, \mathrm{~s}$ \\
\hline \multirow[t]{3}{*}[\operatorname{Ir}(\mu-\mathrm{Cl})(\mathrm{COD})]{$_{2}\left(\mathrm{D}_{2 \mathrm{~h}}\right)$} & C1-C2 & 1.97 & C1, 70.7; C2, 70.7 & $\mathrm{C} 1, \mathrm{sp}^{2.15} ; \mathrm{C} 2, \mathrm{sp}^{2.15}$ \\
\hline & C1-H1 & 1.96 & C1, 78.2; H1, 62.4 & $\mathrm{C} 1, \mathrm{sp}^{2.79} ; \mathrm{H} 1, \mathrm{~s}$ \\
\hline & C2-H2 & 1.96 & C2, 78.2; H2, 62.4 & $\mathrm{C} 2, \mathrm{sp}^{2.79} ; \mathrm{H} 1, \mathrm{~s}$ \\
\hline
\end{tabular}

is more electropositive than Rh and as such it populates carbon with more electron than Rh, thus decreasing the bond order which in return increases the bond length. This consequently resulted in shift to lower wavenumbers for such vibrational modes for coordinated olefinic $\mathrm{C}=\mathrm{C}$ with $\mathrm{Ir}$ than $\mathrm{Rh}$.

\section{Conclusion}

Both vibrational and H-NMR spectroscopic investigation reveals complex of di- $\mu$-chlorobis(1,5-cyclooctadiene) of iridium (I) and rhodium (I) to be of the same geometry. The single-molecule vapor-phase density functional theory (DFT) calculation for the fully optimized structures of both complexes shows that $D_{2}$ structure is more stable than $D_{2 h}$ by 5 - $6 \mathrm{kcal} / \mathrm{mol}$. In contrast, the spectroscopic analysis study affirms that the two complexes retain their higher $D_{2 h}$ symmetry in the solid phase. Theoretical calculations as well as experiment show greater total $(\sigma+\pi)$ metal-olefin interaction for iridium complex.

\section{Acknowledgements}

The authors express their sincere appreciation of the financial support provided by King Abdulaziz City of Science and Technology (KACST) under the funded project (T-K-11-630).

\section{References}

[1] Garcia, M.P., Millan, J.L. and Esteruelas, A. (1987) Rhodium (I) Complexes with the 2,2’-Bipyrimidine Ligand. 6, 1427-1431.

[2] Mas-marza, E., Sanau, M. and Peris, E. (2006) Synthesis and Reactivity of New Complexes of Rhodium and Iridium with Bis(dichloroimidazolylidene) Ligands. Electronic and Catalytic Implications of the Introduction of the Chloro Substituents in the NHC Rings. 12, 3063-3069.

[3] Chen, T., Liu, X.-G. and Shi, M. (2007) Synthesis of New NHC-Rhodium and Iridium Complexes Derived from 
2,2'-Diaminobiphenyl and Their Catalytic Activities toward Hydrosilylation of Ketones. Tetrahedron, 63, 4874-4880. http://dx.doi.org/10.1016/j.tet.2007.03.150

[4] Ibers, J.A. and Snyder, R.G. (1962) Crystal Structure of the Dimer of Rhodium Chloride 1,5-Cyclooctadiene. Acta Crystallogr, 15, 923-930. http://dx.doi.org/10.1107/S0365110X62002479

[5] De Ridder, D.J.A. and Imhoff, P. (1994) Di- $\mu$-chloro-bis[(cis,cis- $\eta 4-1,5$-cyclooctadiene)rhodium(I)]: A Redetermination. Acta Crystallogr. Sect. C Cryst. Struct. Commun, 50, 1569-1572. http://dx.doi.org/10.1107/S0108270194001459

[6] Cotton, F.A., Lahuerta, P., Sanau, M. and Schwotzer, W. (1986) Air Oxidation of Ir, (C1), (COD) 2 (Ruby Form) and Its Oxidation Product, Ir2C12 (COD) 2 (p2-OH) 2 (p2-0). Inorganica Chim. Acta, 120, 153-157. http://dx.doi.org/10.1016/S0020-1693(00)86102-2

[7] Barna, G.G. and Butler, I.S. (1978) Vibrational Spectra of 1,5-Cyclooctadiene, Di- $\mu$-chlorobis[(1,5-cyclooctadiene) rhodium(I)], Di- $\mu$-chlorobis[(1,5-cyclooctadiene)copper(I)] and Bis(1,5-cyclooctadiene)copper(I) Perchlorate. J. Raman Spectrosc., 7, 168-172. http://dx.doi.org/10.1002/jrs.1250070312

[8] Wertz, D.W. and Moseley, M.A. (1980) Vibrational Study of the Metal-Olefin Bond in 1,5-Cyclooctadiene Complexes of Rhodium(I), Palladium(II), and Platinum(II). Inorg. Chem., 19, 705-708. http://dx.doi.org/10.1021/ic50205a025

[9] Frisch, M.J., et al. (2009) Gaussian 09, Revision B. 01. Gaussian, Inc., Wallingford. 